\title{
To harass or to respect: the economy of male persistence despite female refusal in a damselfly with scramble mate competition
}

\author{
Mingzi Xu $\oplus^{1,2} \&$ Ola M. Fincke $\mathbb{1}^{1^{*}}$ \\ ${ }^{1}$ Department of Biology, The University of Oklahoma, Norman OK, USA \\ ${ }^{2}$ Department of Ecology and Evolutionary Biology, University of Minnesota, St. Paul, MN, USA \\ *Corresponding author. Email: fincke@ou.edu
}

Research Article

O OPEN ACCESS

This article is distributed under the terms of the

Creative Commons

Attribution License,

which permits unrestricted use, distribution, and reproduction in any medium, provided the original author and source are credited.

Published: 10 January 2022

Received: 5 October 2021

Accepted: 25 November 2021

Citation:

Xu \& Fincke (2022):

To harass or to respect:

the economy of male persistence despite female refusal in a damselfly with scramble mate competition International Journal of

Odonatology, 25, 7-15 doi:10.48156/1388.2022.1917154

Data Availability Statement: All relevant data are within the paper and its Supporting Information files.

\begin{abstract}
In sexual conflict, males are often thought to gain fitness benefits from harassing females over mating. Yet when harassment itself incurs costs to males and if alternative, receptive females are available in a local population, theory predicts that when confronted with a female refusal, a male's choice of persisting or retreating is determined in part by the likelihood of achieving a mating. We tested that prediction in the damselfly Enallagma hageni, whose males compete by intense scramble competition, resulting in widespread mating harassment toward females, which have a high level of control over mating. Using captive individuals of $E$. hageni in outdoor insectaries, we quantified male persistence in mating after refusals by pre- and post-oviposition focal females whose egg content we quantified after observations. We documented a novel, context-dependent head-turning refusal signal of sexual non-receptivity, most often displayed in tandem pairs by post-oviposition females that typically carried few mature eggs for males to fertilize. Male persistence was less likely to result in mating with post-oviposition females compared with preoviposition females carrying a clutch of mature eggs. Accordingly, males were less likely to persist following refusal signals given by post-oviposition females, supporting the theoretical prediction. Compared with a refusal signal known as wing spread, head-turning was significantly more effective in deterring harassing males. Our results suggest that despite on-going sexual conflict over mating, cooperation benefits both sexes when females use the honest signal of non-receptivity because they carry few mature eggs that males could fertilize.
\end{abstract}

Keywords. Enallagma hageni, Odonata, courtship persistence, female refusal signals, mating harassment, optimal strategy, sexual conflict

\section{Introduction}

The evolutionary interests of the two sexes are rarely identical (Arnqvist \& Rowe, 2005). Sexual conflict occurs when selection drives males and females towards separate optima (Parker, 2006). One common form of sexual conflict is the conflict over mating, where males, with relatively cheap gamete production, tend to maximize the number of matings, whereas females, limited by the number of expensive eggs they can produce, usually do not want to mate as often (Bateman, 1948). As a result, a male may not respect a female's refusal and attempt to mate with her, resulting in male mating harassment towards females (Arnqvist \& Rowe, 2005). Costs of mating harassment to females are common, consisting of lost time (e.g. Sudaresan, Fischhoff \& Rubenstein, 2007), physical damage to females (e.g. Mühlhauser \& Blanckenhorn, 2002; Crudginton \& Siva-Jothy, 2000), shortened longevity (e.g. Nandy et al., 2013), and reduced fecundity (e.g. Sakuai \& Kasuya, 2008). 
In the context of sexual conflict, male mating harassment is often treated as an inherent characteristic of a species, assumed to generally provide a fitness benefit for males. Indeed, the costs to males of performing harassment is commonly ignored in models of sexual conflict (Green \& Madjidian, 2011) despite more nuanced fitness consequence of such harassment. Factors that can tip the cost-benefit balance of harassment behavior for males include time expenditure (Singer et al., 2000), risk of predation (e.g., Rowe et al., 1994), cannibalism (e.g., Arnqvist \& Henniksson, 1997; Fincke, 1987) or physical damage (Stewart-Fox \& Whiting, 2005), availability of receptive females (e.g. Ide, 2011, Wirklund \& Forsber, 1986), and level of female control over mating (e.g., Inceoglu et al., 2003). Hence, even in species where competition for mates among males is intense and male mating harassment has been well documented, persisting after a female refusal may not always be the optimal male strategy. Indeed, in a theoretical model of courtship persistence towards unreceptive females, the optimal persistence level of males is determined by the likelihood of encountering alternative receptive females and the probability of achieving mating through persisted courtship (Parker, 1974). This model is easy to understand. While spending time courting an unreceptive female, a male loses potential fitness gains with other receptive females. Thus, when it is more likely for males to encounter receptive females than unreceptive ones, it is more favorable for males to respect a female's rejection and leave. Under a given receptive to unreceptive female ratio, the more likely males can achieve fertilization through harassment, the more favorable harassment becomes to male fitness. Conversely, under a high level of females control over mating, the model predicts that the optimal persistence level should be low and male courtship or mate searching may consist of brief checks for female receptivity (e.g. Schwagmeyer, 1995). Although these predictions have been supported by empirical data from several organisms with a relatively low level of sexual conflict over mating (e.g., Bergström \& Wiklund, 2005, Mühlhauser \& Blanckenhorn, 2002), it is unclear in species where male mating harassment is prevalent, whether male behavior follows similar principles.

The non-territorial damselfly Enallagma hageni offers an ideal system for testing predictions of optimal persistence by mate-searching males. In this species whose males must search for mates against a visually cluttered background, females can be either male-like blue or green, similar in color to the vegetation background (Schultz \& Fincke, 2013). This female-specific color polymorphism is thought to have evolved in the context of harassment reduction by females (Van Gossum et al, 2008). Male-male scramble competition for mates is intense; under natural conditions less than half of males succeed in mating during their lifespan (Fincke, 1982). Compared with the 2.5 days males require to return to breeding sites on average, females on average require about 5 days to mature a second clutch of eggs (Fincke, 1994). Thus, a large proportion of females encountered by males are not receptive to mating on a given day. As a result, in this species, male mating harassment towards unreceptive females is common and can incur costs to females in the form of disturbance during foraging or resting (Fincke, 2015). Females oviposit underwater and may mate multiply on a given day, typically if they resurface prematurely from oviposition with eggs still left to lay. By mating with a second male, females may be rescued from drowning by males awaiting a chance to fertilize any of their remaining eggs (Fincke, 1984, 1986).

Compared with many animal species whose females suffer forced copulations (reviewed by Ringo, 1996), E. hageni females, like zygopterans more generally, have a relatively high level of proximal control over mating (reviewed by Fincke, 1997). After a male takes a female in tandem by engaging his abdominal claspers with the mesostigmal plates on a female's thorax, copulation depends on the female raising her abdomen to the male's second abdominal segment such that she aligns her genital pore on the $8^{\text {th }}$ abdominal segment with the male penis (Miller \& Miller, 1981). A female in tandem position can avoid mating simply by refusing to lift her abdomen. Once in tandem with a male, females can physically break tandem by moving down a stem to increase the angle between male claspers and her mesostigmal plates (Fincke, 2015; Rebora et al., 2018).

Under natural conditions, upon encountering an approaching male, females can prevent being detected by using avoidance behaviors such as hiding by moving to the other side of a stem, or flying away (Fincke, 2015; Piersanti et al., 2021; Sánchez-Guillén et al., 2017). After detection by a male, those same behaviors can also prevent males from persisting in harassment (Piersanti et al., 2021). Females also show two types of refusal signals, which are distinct from the above avoidance behaviors because neither removes the opportunity for males to persist. The first type of refusal signal is a lateral wing spread, often accompanied with the abdomen lifted dorsally and the abdominal tip curled ventrally (Corbet, 1999). A second refusal signal occurs after tandem formation with a male, when a female gently turns her head in and out of the plane of her abdomen along the anterior-posterior axis, sometimes together with bobbing the abdomen up and down ever so slightly (hereafter, 'head-turning', see video No means no.mov). Such head turning does not generate sufficient force to break the tandem. Rather, we consider this behavior as a signal that modifies male response through coding of refusal intention. Others have noted the behavior in various genera (Enallagma, Barnard et al., 2017; Tennessen, 1975, Ischnura, Piersanti et al., 2021) or similar elements of it such as abdomen shaking (Nehalennia, Forbes, et al. 1995). Those behaviors were thought to signal a lack of female receptivity, but information about the egg count of the signalers was lacking. 
In this study, using E. hageni, we examined male responses (i.e., persist or respect) to female refusal signals. We quantified whether male persistence that resulted in matings with females carrying a full egg load differed from such persistence with females that had already laid their clutch. We then tested the hypothesis that given a female refusal, a male's persistence depended on the likelihood of achieving mating. We predicted that male persistence decreases with his likelihood of achieving a mating.

\section{Material and methods}

Our study was conducted between June 23 and August 2, 2012, near the shore of Duck Lake, a natural lake at Chase Osborn Preserve on Sugar Island, MI, USA $\left(46.40529^{\circ} \mathrm{N}, 84.20747^{\circ} \mathrm{W}\right)$, where the green morph is typically the majority (e.g. 68\%, Xu, and Fincke, 2011). We observed responses to male attention from three types of females: sexually mature virgins, females mated once but not allowed to oviposit, and females mated and allowed to oviposit (hereafter denoted as virgin, mated and oviposited treatment, respectively). When the two refusal signals of wing spread and head turning were exhibited, we noted whether the male persisted or left and whether his persistence resulted in mating. Females used in the virgin and mated treatments were collected as young tenerals and kept in a large outdoor insectary $(1.8 \times 3.6 \times 1.8 \mathrm{~m})$ until they developed mature coloration, signifying sexual maturation. We dissected three virgin females reared in the insectary on the first day they developed full adult body coloration as well as all females in the virgin and mated treatment (after observations) to confirm that they all had abdomens full of mature eggs. Wild-caught small flies (species not noted) from the surrounding forest were provided twice a day as food. Teneral and adult E. hageni were frequently observed to feed on these small flies at the study site. For the post-oviposition treatment, females at the lakeshore were collected in tandem or mating, mated with a unique male in an outdoor insectary, and placed in plastic jars overnight with wet filter paper as an oviposition substrate. After they finished oviposition, they were retained in the insectary until they were observed in behavioral trials. Afterwards, we counted the number of eggs each female laid and the number of mature eggs remaining inside her abdomen using a dissecting microscope. All males used in the experiment were caught as mature males from the lakeshore.

We conducted focal observations on 10 females after oviposition ( 5 blue, 5 green) and nine sexually mature, virgin females ( 4 blue, 5 green). Among the nine virgin females, six (3 blue, 3 green) were observed again after they had mated once with unique males. We also observed an additional green female after she mated once but had not oviposited. Observations were conducted in a small outdoor insectary $(1.8 \times 1.8 \times 1.8 \mathrm{~m})$ locat- ed in a small forest gap on sunny days between 1100 and 1600 hrs. Density in the insectary during observation trials was kept at 16 males and four females for five virgin females and 10 males and four females for the remaining 15 focal females. All non-focal females in a trial were caught from the lakeshore. To maximize male interactions with the focal female, we painted the mesostigmal plates of non-focal females with clear fingernail polish, which prevented males from forming tandem pairs with them. Observation duration of each focal female ranged between 20 and 105 min and ended when the focal female did not interact with any male for $15 \mathrm{~min}$. If a female began copula, we gently separated the pair so that the focal female could continue to interact with additional males during observations. We numbered focal females on left forewing using an indelible marker and painted males with unique color dots on the left forewing to enable identification during flight.

During focal observations, an interaction bout began with a male's detection of a female, signified by his hovering or grabbing her. We recorded whether a focal female displayed avoidance behavior, refusal signals, or did not respond, signifying acceptance. Avoidance behaviors were categorized as escape if the female flew away, darted into vegetation, changed perch or moved around it. Refusal signals were wing spread and/or abdomen curl ventrally, head turning with or without abdomen bobbing, and in one case, lowering of the wings. If a refusal signal was given, we also recorded whether the male respected the signal (i.e. retreated after a wing spread, or released the female from tandem after head turning) or persisted, as well as whether the interaction bout resulted in mating. If a male had multiple interaction bouts with a focal female within $15 \mathrm{~min}$, only the first interaction was counted.

\section{Statistical analyses}

Because six focal females were observed in both virgin and mated treatments (Figure S1), to determine whether the virgin and mated treatments differed in how females reacted to male detections, we used a generalized linear mixed model (GLMM) with a Poisson error distribution, female ID as a random variable, treatment (virgin versus mated) as the explanatory variable, and female reaction (i.e. acceptance, avoidance, or refusal signals) as repeated measures within female ID for the response variable. We used total number of male detections as an offset variable to control for the total number of male-female interactions without sacrificing degrees of freedom (Zuur et al., 2009). We pooled the virgin and mated treatments, creating the pre-oviposition treatment in which all females were independent samples that carried mature eggs. To test for the effect of treatment (pre- and post-oviposition), morph (blue and green) and their interaction (i.e., explanatory variables), on female reactions to male detection, we 
used a generalized linear model (GLM) with a Poisson error distribution and female reaction (refusal, avoidance, or acceptance) as the response variable, with total male detections as an offset variable. We used a GLM with Poisson error distribution to further test for treatment, morph, and their interaction effects (explanatory variables) on two male response variables: 1) the number of male persistence events following female refusal signals, and 2) the number of matings achieved by males given male persistence. For 1), we used the number of female refusal signals as the offset variable; for 2), we use the number of male persistence events as the offset variable. Interaction terms were dropped if any main effect was not significant. Finally, to determine if pre- and post-oviposition females differed in their use of wing spread and head-turning, we used a two-sample Welch's $t$ test to compare the proportion of wing spread and head turning between treatments (pre- and post-oviposition). To determine if males were more likely to persist after receiving a wing spread than a head turning signal, we used a onesample Welch's $t$ test to compare the proportions of male persistence between the two signal types. We first calculated the difference between the proportion of male persistence following wing spread and head turning for each focal female, then tested whether the difference was significantly greater than zero. All proportional data were arcsine square root transformed. All statistical tests were performed in $\mathrm{R}$ (version 3.6.3, $R$ Core Team, 2020). Throughout, means are expressed with standard error.

\section{Results}

On average, focal females in the post-oviposition treatment laid $382 \pm 37.66$ eggs (range: $186-528$, Fig 1 ), with an average of $25 \pm 16.32$ mature eggs remaining in the body (range: 1-49) before they were observed.

Using data from the six females that were measured in both virgin and mated treatments, virgin females were more likely to use avoidance behaviors $\left(\chi^{2}=10.22, d f=1, p=0.001\right.$, Figure S1), whereas after mating, females were more likely to display refusal signals $\left(\chi^{2}=53.40, \mathrm{df}=1, p<0.001\right)$. Combining virgin and mated treatments into the pre-oviposition treatment, acceptance, avoidance behaviors and refusal signals differed significantly between females before and after oviposition and between color morphs ( $\mathrm{Ta}-$ ble 1). There was also a morph by treatment interaction for all three response categories (Table 1). Specifically, post-oviposition, females were less likely to accept male attention and more likely to use avoidance behaviors or display refusal signals (Figure 2). In addition, post oviposition, blue females were more likely to display refusal signals whereas green females were more likely to use avoidance behaviors; this difference was reversed in the pre-oviposition treatment (Figure 2).
Table 1. Results from generalized linear models showing treatment (pre- and post-oviposition), female color morph (blue and green), and interaction effects on the frequency of females exhibiting acceptance, avoidance, and refusal signals controlling for male detection.

\begin{tabular}{lrrr}
\hline & $\mathbf{\chi}^{\mathbf{2}}$ & $\mathbf{d f}$ & $\mathbf{p}$ \\
\hline Acceptance & & & \\
Treatment & 6.58 & 1 & 0.01 \\
Morph & 165.46 & 1 & $<0.001$ \\
Treatment*morph & 11.43 & 1 & 0.001 \\
Avoidance & & & \\
Treatment & 129.71 & 1 & $<0.001$ \\
Morph & 180.82 & 1 & $<0.001$ \\
Treatment*morph & 67.9 & 1 & $<0.001$ \\
Refusal signals & & & \\
Treatment & 401.4 & 1 & $<0.001$ \\
Morph & 437.66 & 1 & $<0.001$ \\
Treatment*morph & 243.64 & 1 & $<0.001$ \\
\hline
\end{tabular}

Given female refusal signals, male persistence was more likely to result in mating with females prior to oviposition than with post-oviposition females $\left(\chi^{2}=\right.$ $11.42, \mathrm{df}=1, p=0.001$, Figure 3 ) and there was no difference between color morphs $\left(\chi^{2}=0.02, \mathrm{df}=1, p=\right.$ $0.88)$. As predicted, males were more likely to persist in face of refusal signals towards females prior to oviposition $\left(\chi^{2}=28.89, \mathrm{df}=1, p<0.001\right.$, Figure 3 ). In addition, males were generally more likely to persist if the refusal signals were from a green female than a blue female (proportion of persistence given refusal: green $=$ $42.60 \%$, blue $\left.=37.04 \%, \chi^{2}=56.4, \mathrm{df}=1, p<0.001\right)$. We also detected a significant morph by treatment interaction $\left(\chi^{2}=4.77, \mathrm{df}=1, p=0.03\right)$, as males were more likely to persist towards blue females in the pre-ovipo-

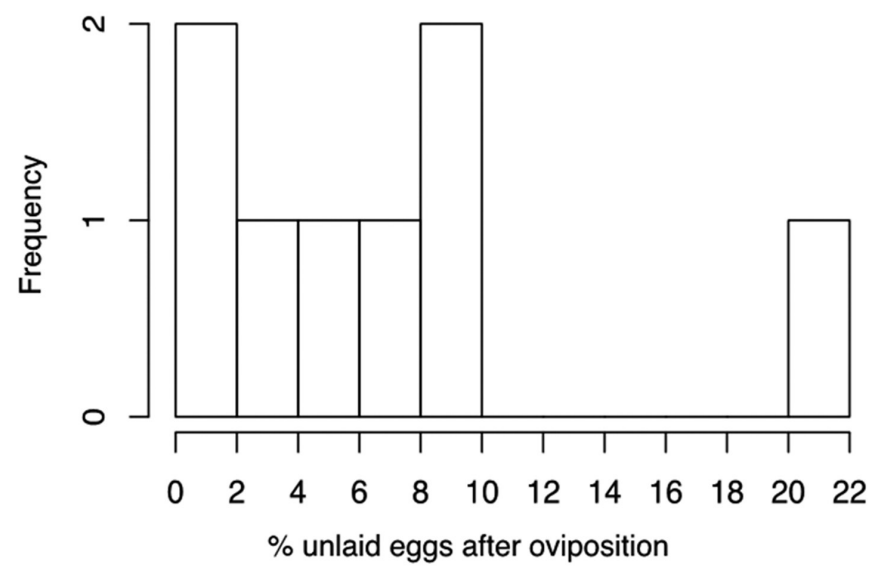

Figure 1. Distribution of proportion of mature eggs remaining in the abdomen in post-oviposition females; the extreme individual with $20 \%$ was a blue female that had a total of 235 eggs. 
sition treatment and this pattern was reversed in the post-oviposition treatment (Figure 3).

The use of each type of refusal signal was context dependent. Females' use of wing spread did not differ between pre- $(n=23)$ and post-oviposition $(n=40)$ treatments $(t=0.13, \mathrm{df}=17.9, p=0.90$, Figure $4 \mathrm{a})$. In contrast, post-oviposition females were more likely to display head-turning $(n=21)$ than pre-oviposition females ( $\mathrm{n}=10, t=-2.38, \mathrm{df}=17.4, p=0.03$, Figure 4a). Male responses differed between the two types of refusal signals regardless of oviposition status: males were more likely to persist following wing spread and to respect following head turning ( $t=9.14$, df $=12$, $p<0.001$, Figure 4b). Specifically, out of 32 cases of female head turning, males persisted in only one case (8.93\%), compared to 46 out of 77 (63.19\%) cases of female wing spreads. In the one case where a male persisted and achieved mating following head turning, a blue female had 49 of 235 (20.9\%) mature eggs left in her abdomen after oviposition, compared to an average of $4.9 \%$ remaining eggs from other post-oviposition females (Figure 1).

Of the 10 pre-oviposition focal females, six were detected more than once by a given individual male during observations. Four of those six females (67\%) accepted a male which they subsequently refused one or more times. The remaining two females refused a different, given male twice.

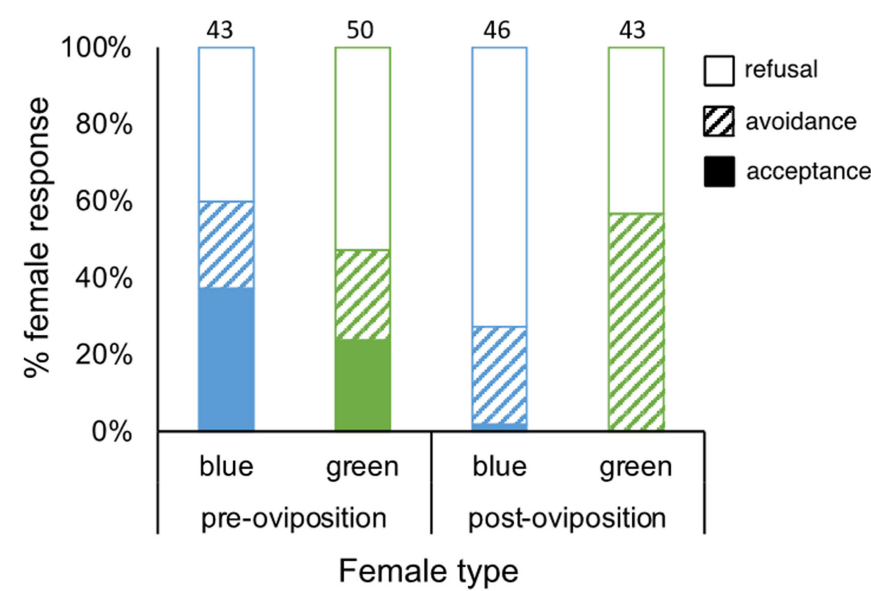

Figure 2. Proportions of responses after male detection, categorized as acceptance, avoidance behaviors, and refusal signals, from focal females of the two color morphs in the pre- ( $n=4$ blue and 5 green females) and post- oviposition treatments ( $n=5$ blue and 5 green females). Numbers are total female responses by type.

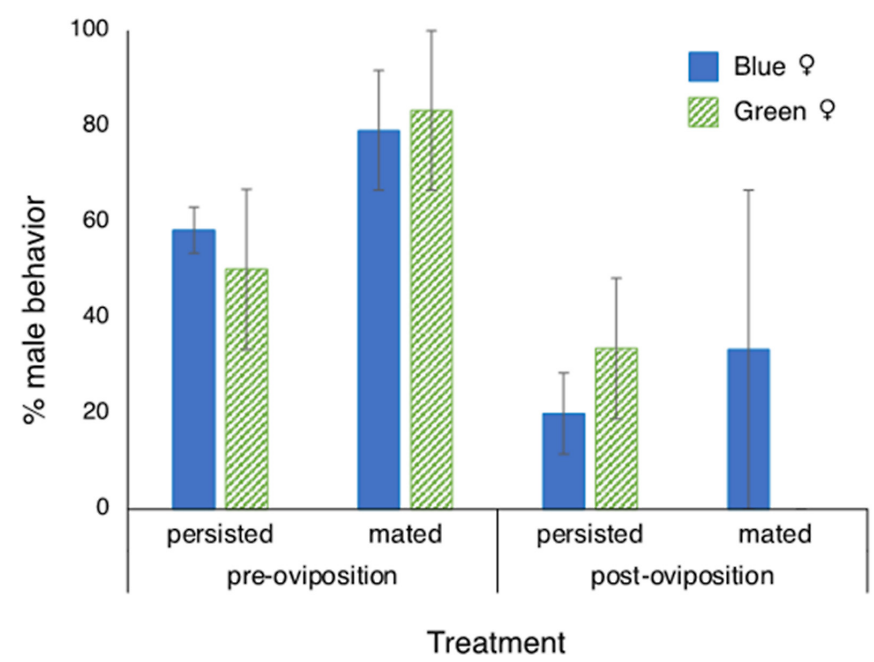

Figure 3. Mean \pm s.e. proportion of male persistence following female refusal signals and matings achieved following male persistence with focal females of the two color morphs in the pre- and post-oviposition treatments.
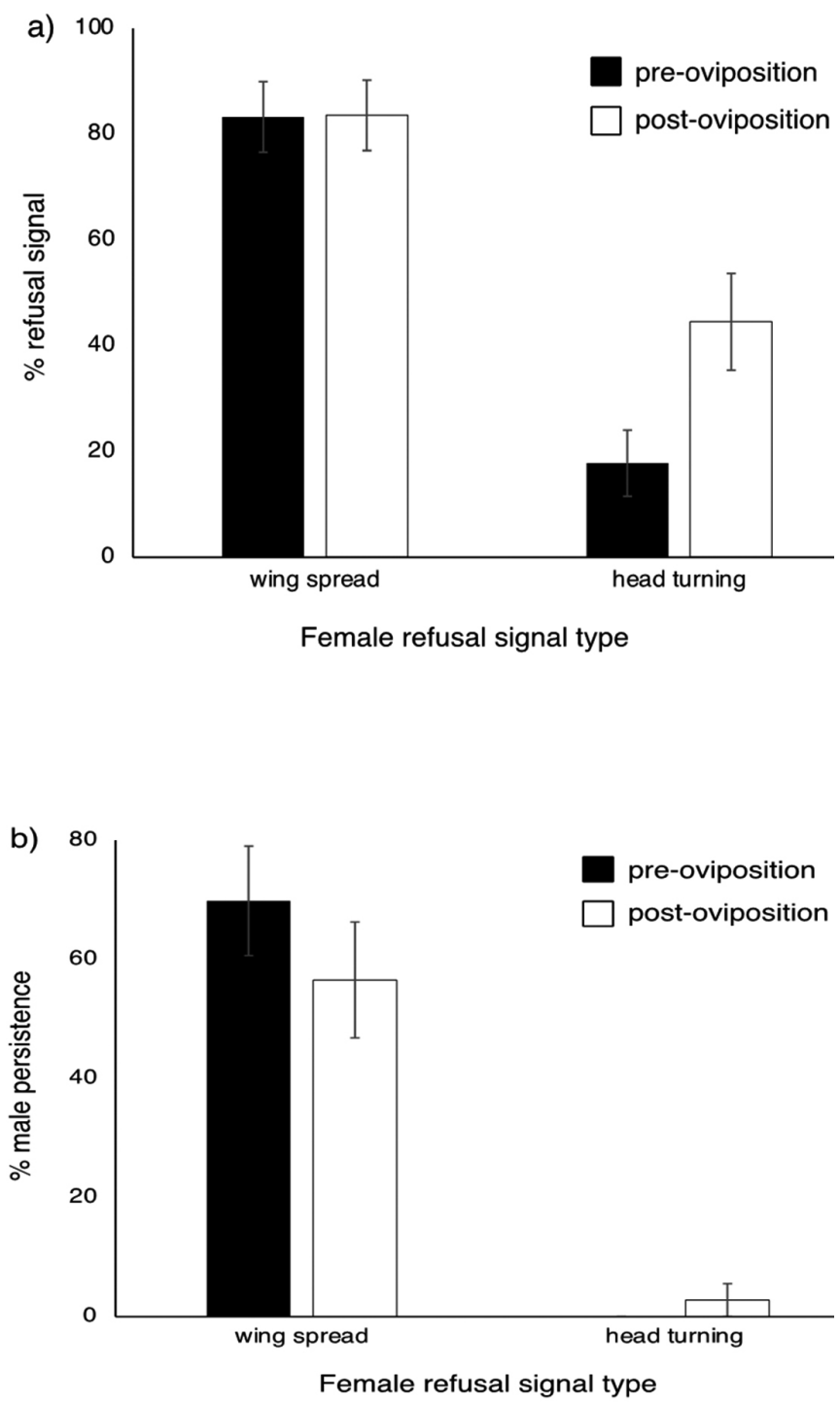

Figure 4. (a) Mean \pm s.e. proportion of wing spread and head turning in interactions with males where refusal signals were displayed in the pre- and post-oviposition treatments. Note that the two categories are not mutually exclusive because a female can display both types during the same interaction bout with a male and (b) Mean \pm s.e. proportion of male persistence following wing spread and head turning. Color morphs were pooled within treatment. 


\section{Discussion}

In sexual conflict, males are thought to benefit from harassing females (Arnqvist \& Rowe, 2005). However, when harassment incurs costs to males and alternative, receptive females are available, harassing a female that signals a refusal may not be the best choice because a male may gain a mating more readily by retreating and searching for other females that may be receptive. Whether or not a male should persist in harassing or retreat should depend on the probability of achieving mating by those two alternative choices (Parker, 1974). Our results on Enallagma hageni, whose mating system has scramble competition among males and high harassment rates on females in the wild were consistent with Parker's prediction. Male persistence following female refusal signals was significantly less likely to result in a mating when the signal was given by postoviposition females than pre-oviposition ones. Males indeed were more likely to persist with a female before she had oviposited than afterwards (Figure 3). Although we also detected a color morph effect and a morph by treatment interaction for both female responses to male detections and male reactions to female refusal signals, due to the small sample sizes and the unnatural visual background of the insectary screen, which can unnaturally bias the signal apparency of female morphs (see Fincke, 2015), we cannot draw biological meaningful conclusions from those results. Due to their color differences and the context in which the green and blue females are encountered (Schultz \& Fincke, 2013; Fincke, 2015), under natural conditions, relative to blue females, green females are less likely to be detected by males, but once detected, are more likely to be recognized as potential mates (Piersanti et al., 2021).

Our finding that the probability of achieving a mating affected male reactions to female refusal signals is consistent with findings from a number of butterflies, whose males court females, and which, like female E. hageni, have considerable control over mating. In the cabbage white butterfly Pieris, when courted by a male, recently mated, unreceptive females typically displayed a spread wing-elevated abdomen refusal posture, during which they involuntarily release a volatile antiaphrodisiac transferred from the male she mated with previously (Andersson et al., 2000). In this genus, males are incapable of forcing females to mate. Accordingly, males typically respect this multimodal refusal signal (Andersson et al., 2003, 2004). Similarly, in the marsh fritillary butterfly Euphyas aurinia, unreceptive females display a refusal signal with wide wing fluttering and wing fanning, an indication of chemical signaling. Males typically respect this signal; those that persist rarely achieve mating (Pinzari et al., 2019). In the small copper butterfly Lycaeas phlaeas daimio whose females mate only once in their life, unreceptive females display wing closing as a refusal signal. Despite differences in the specific form of the female signal, these males also typically respect the female refusal (Ide, 2011). These findings, together with our results, are consistent with refusal signals indicative of female non-receptivity also found in cockroaches, fruit flies and crickets (reviewed by Ringo, 1996). Unlike butterflies whose males court females with little sexual harassment, E. hageni males, like those of most coenagrionids, do not court females. Instead, there is high level of scramble competition among males for females and male mating harassment is common under natural conditions (e.g. Fincke, 2015; Piersanti et al., 2021; Sánchez-Guillén et al., 2017; Van Gossum et al., 2001). Thus, our results offer the novel insights that Parker's (1974) prediction is not only applicable to different mating systems, but that high levels of male-male competition for mates resulting in intense sexual conflict does not completely override the economic principles that govern male reactions to refusal signals.

Importantly, the two types of refusal signals considered in our study, wing spread and head turning, differed in the context in which they were displayed and their effectiveness in deterring males. Specifically, wing spread was more commonly displayed than head turning both before and after oviposition and males frequently persisted following wing spread in both treatments (Figure 4a, b), suggesting low effectiveness in deterring males by wing spread. Wing spread has been reported in numerous damselfly species (reviewed by Corbet, 1999) and is used not only by mature females but by males and immature females to repel male advances across different contexts (Piersanti et al., 2021; Sánchez-Guillén et al., 2017; Waage, 1984). The effectiveness of these signals also varies both among and within species (Waage, 1984; see Fincke, 1987, for its probable use in mate solicitation). Wild, sexually receptive female Ischnura elegans that are involved foraging or feeding at the time of male detection are known to use wing spreads even though they may mate with another male later on (e.g., Piersanti et al., 2021). In contrast, head turning was more likely to be displayed by post-oviposition females and once displayed, in only one case did a male not respect it (Figure $4 a, b$ ). As this signal can only be displayed by a female in tandem with a male, its usage is limited to a much more specific context and it is much more effective in deterring males compared to wing spread. These results suggest that the two refusal signals differ in their information content and function. As head turning was more likely to be displayed by females without any or only few mature eggs and almost perfectly predicted a male's failure to mate in our study, we suggest that this signal is an honest signal of a female's unreceptivity to mating, either due to lack of eggs or females being involved in other activities, such as foraging or feeding, at the time of male detection. Whereas the duration of a wing spread is on the order of seconds or less (personal observations), head-turning typically requires a minute or more of effort by a female before she is released by the male (see No means no video). Among both pre- and post-oviposition females (Figure $4 \mathrm{~b}$ ), the only case in which a male 
persisted after a head turning signal was with a blue female that still had $20 \%$ of her mature eggs remaining after oviposition (Figure 1). In nature, that female is analogous to one that would still be receptive to mating after resurfacing before laying all her mature eggs. The above male was the only one, following 31 total cases of head-turning, that subsequently persisted in trying to mate, suggesting a benefit for males persisting with females resurfacing from oviposition. Under natural conditions in I. elegans, whose males do not harass ovipositing females, the few observed cases of head-turning led males to release tandem females; in one case a male even released a head-turning female in copula just before she laid eggs (Piersanti et al., 2021). More attention to this female signal and males' response to it under natural conditions is needed to understand why males almost always respected head-turning.

Although head-turning displayed by pre-oviposition females could be a way for females to choose among males based on their phenotypes, this seems unlikely given our results. The majority of females that were detected by the same male multiple times rejected males with whom they had earlier mated. Some evidence for possible mate choice comes from the finding that male clasper characters differed between tandem or mated males and unmated males in E. hageni (Siepielski et al., 2018). However, the direction of the difference changed between study years and all tandems were assumed to have resulted in copula, which was often not the case in our results here nor the case under natural conditions (Fincke, 2015; Piersanti et al., 2021). In contrast, headturning that signals an Enallagma female's non-receptivity to tandem males of the wrong species, offers a case more consistent with our results. Sympatric female $E$. anna and $E$. carunculatum use head-turning to resist mating with heterospecifics and hybrids (Barnard et al., 2017, see also Tennessen, 1975). Because heterospecific tandems are not uncommon among coenagrionids (e.g., Forbes et al., 1995; Paulson, 1974; SánchezGuillén et al., 2011, Tennessen, 1982) and the above hybrids were less fit (Barnard et al., 2017), a female's head turning signal should offer a cue to heterospecific males that persistence would result in time wasted.

Our results offer preliminary insights for sexual conflict and its resolution. In the context of sexual conflict, the relationship between males and females is typically viewed as antagonistic. As our results show, however, this view is overly simplistic. If retreating after receiving female head turning signals gives males a better chance to achieve a mating by searching for alternative, receptive females, then the display of this refusal signal by females and the respect of such signals by males can be considered mutually beneficial when females have few eggs to fertilize, and hence, cooperative amidst sexual conflict over mating. Thus, head turning, and more generally, other similar refusal signals and the male reactions to them may have evolved as a resolution to sexual conflict over mating, similar to the case of cabbage white butterflies (Anderson, 2000). Testing this idea awaits empirical data on the fitness consequences for males of persisting and respecting following female refusal signals. Although modeling work has offered us an understanding of factors governing male responses to refusal signals, empirically, costs of harassment behaviors to males have rarely been measured (Green \& Madjidian, 2011), limiting our ability to understand whether differential male responses to female refusal signals in different contexts may be adaptive. Our study thus calls for research that focuses on the fitness consequences of different options to males, knowledge that has the potential to offer a more sophisticated understanding of the relationship between males and females in the context of sexual conflict.

\section{Data accessibility}

$\mathrm{R}$ script for running statistical analyses and original data are available for downloading at https://github.com/MingziXu/Enallagma_ refusal.

\section{Acknowledgments}

We thank Erika Eldrenkamp for assistance in fieldwork. We are grateful to the University of Michigan Biological Station for logistical support and permission to work at the Chase Osborn Reserve on Sugar Island. We thank Tom Sherratt and two anonymous reviewers for comments that improved the manuscript.

\section{Funding support}

This work was supported by National Science Foundation (grant IOS-06461679 to OMF and grant IOS-1209069 to OMF and MX), The University of Michigan Biological Station (Chase Osborn Fellowship to $\mathrm{M}$. Xu), and The University of Oklahoma (Adams Scholarship and Loren Hill Research Fund to M. Xu).

\section{References}

Andersson, J., Borg-Karlson, A. K. \& Wiklund, C. (2000). Sexual cooperation and conflict in butterflies: a male-transferred anti-aphrodisiac reduces harassment of recently mated females. Proceedings of the Royal Society of London. Series B: Biological Sciences, 267, 1271-1275. doi:10.1098/rspb.2000.1138

Andersson, J., Borg-Karlson, A. K. \& Wiklund, C. (2003). Antiaphrodisiacs in pierid butterflies: a theme with variation! Journal of chemical ecology, 29, 1489-1499. doi:10.1023/ A:1024277823101

Andersson, J., Borg-Karlson, A. K. \& Wiklund, C. (2004). Sexual conflict and anti-aphrodisiac titre in a polyandrous butterfly: male ejaculate tailoring and absence of female control. Proceedings of the Royal Society of London. Series B: Biological Sciences, 271, 1765-1770. doi:10.1098/rspb.2003.2671

Arnqvist, G. \& Henriksson, S. (1997). Sexual cannibalism in the fishing spider and a model for the evolution of sexual cannibalism based on genetic constraints. Evolutionary Ecology 11, 255-273. doi: 10.1023/A:1018412302621

Arnqvist, G. \& Rowe, L. (2005). Sexual Conflict. Princeton University Press, Princeton. doi:10.1515/9781400850600

Barnard, A., Fincke, O. M., McPeek, M. A. \& Masly, J. P. (2017). Mechanical and tactile incompatibilities cause reproductive isola- 
tion between two young damselfly species. Evolution 71, 24102437. doi:10.1111/evo.13315

Bateman, A. J. (1948). Intra-sexual selection in Drosophila. Heredity 2, 349-368. doi:10.1038/hdy.1948.21

Bergström, J. \& Wiklund, C. (2005). No effect of male courtship intensity on female remating in the butterfly Pieris napi. Journal of Insect Behavior, 18. doi:10.1007/s10905-005-5605-X

Corbet, P. S. (1999). Dragonflies: Behavior and Ecology of Odonata. Ithaca, N.Y. Comstock Publishing Associates.

Crudginton, H. S. \& Siva-Jothy, M. T. (2000). Genital damage, kicking and early death - the battle of the sexes takes a sinister turn in the bean weevil. Nature, 407, 855-856. doi:10.1038/35038154

Fincke, O. M. (1982). Lifetime mating success in a natural population of the damselfly Enallagma hageni (Walsh) (Odonata: Coenagrionidae). Behavioral Ecology and Sociobiology, 10, 293-302. doi:10.1007/BF00302820

Fincke, O. M. (1984). Sperm competition in the damselfly Enallagma hageni Walsh (Odonata: Coenarionidae): benefits of multiple mating to males and females. Behavioral Ecology and Sociobiology, 14, 235-240. doi:10.1007/BF00299623

Fincke, O. M. (1986). Underwater oviposition in a damselfly (Odonata: Coenagrionidae) favors male vigilance, and multiple mating by females. Behavioral Ecology and Sociobiology, 18, 405-412. doi:10.1007/BF00300514

Fincke, O. M. (1987). Female monogamy in the damselfly Ischnura verticalis Say (Zygoptera: Coenagrionidae). Odonatologica, 16, 129-143.

Fincke, O. M. (1994). Female dimorphism in damselflies: failure to reject the null hypothesis. Animal Behaviour, 47, 1249-1266. doi:10.1006/anbe.1994.1174

Fincke, O. M. (1997). Conflict resolution in the Odonata: implications for understanding female mating patterns and female choice. Biological Journal of the Linnean Society, 60, 201-220. doi:10.1111/j.1095-8312.1997.tb01492.x

Fincke, O. M. (2015). Trade-offs in female signal apparency to males offer alternative anti-harassment strategies for color polymorphic females. Journal of Evolutionary Biology, 28, 931-943. doi:10.1111/jeb.12623

Forbes, M. R. L, Richardson, J. M. L. \& Baker, R. L. (1995). Frequency of female morphs is related to an index of male density in the damselfly Nehalennia irene (Hagen). Ecoscience, 2, 28-33. doi:10. 1080/11956860.1995.11682265

Green, K. K. \& Madjidian, J. A. (2011). Active males, reactive females: stereotypic sex roles in sexual conflict research? Animal Behaviour, 81, 901-907. doi:10.1016/j.anbehav.2011.01. 033

Ide, J.-Y. (2011). Avoiding male harassment: wing-closing reactions to flying individuals by female small copper butterflies. Ethology, 117, 630-637. doi:10.1111/j.1439-0310.2011. 01912.x

Inceoglu, B., Lango, J., Jing, J., Chen, L., Doymaz, F., Pessah, I. N. \& Hammock, B. D. (2003). One scorpion, two venoms: Prevenom of Parabuthus transvaalicus acts as an alternative type of venom with distinct mechanism of action. Proceedings of the National Academy of Sciences, 100, 922-927. doi:10.1073/ pnas.242735499

Miller, P. L. \& Miller, C. A. (1981). Field observations on copulatory behaviour in Zygoptera, with an examination of the structure and activity of male genitalia. Odonatologica, 10, 201-218.

Mühlhauser, C. \& Blanckenhorn, W. U. (2002). The costs of avoiding matings in the dung fly Sepsis cynipsea. Behavioral Ecology, 13, 359-365. doi:10.1093/beheco/13.3.359

Nandy, B., Gupta, V., Sen, S., Udaykumar, N., Samant, M. A., Ali, S. Z. \& Prasad, N. G. (2013). Evolution of mate-harm, longevity and behaviour in male fruit flies subjected to different levels of in- terlocus conflict. BMC Evolutionary, 13, 212. doi:10.1186/14712148-13-212

Parker, G. A. (1974). Courtship persistence and female guarding as male time investment strategies. Behaviour, 48, 157-184. doi:10. 1163/156853974X00327

Parker, G. A. (2006). Sexual conflict over mating and fertilization: an overview. Philosophical Transactions of the Royal Society, B. 361, 35-259. doi:10.1098/rstb.2005.1785

Paulson, D. R. (1974). Reproductive isolation in damselflies. Systematic Zoology, 23, 40-49. doi:10.1093/sysbio/23.1.40

Piersanti, S., Salerno, G., Di Pietro, V., Giontella, L., Rebora, M., Jones, A. \& Fincke, O. M. (2021). Tests of search image and learning in the wild: Insights from sexual conflict in damselflies. Ecology and Evolution, 11(9), 4399-4412. doi:10.1002/ece3.7335

Pinzari, M., Pinzari, M. \& Sbordoni, V. (2019). Make it simple: mating behaviour of Euphydryas aurinia provincialis (Lepidoptera: Nymphalidae). The European Zoological Journal, 86, 220-232. doi:10. 1080/24750263.2019.1629030

R Core Team (2020): $R$ : A language and environment for statistical computing. R Foundation for Statistical Computing, Vienna, Austria. https://cran.r-project.org/

Rebora, M., Frati, F., Piersanti, S., Salerno, G., Selvaggi, R. \& Fincke, O. M. (2018). Field tests of multiple sensory cues in sex recognition and harassment of a colour polymorphic damselfly. Animal Behaviour, 136, 127-136. doi:10.1016/j.anbehav.2017.12.015

Ringo, J. (1996). Sexual receptivity in insects. Annual Review of Entomology, 41, 473-94. doi:10.1146/annurev.en.41.010196.002353

Rowe, L., Arnqvist, G., Sih, A. \& Krupa, J. (1994). Sexual conflict and the evolutionary ecology of mating patterns: water striders as a model system. Trends in Ecology and Evolution, 9, 289-293. doi:10.1016/0169-5347(94)90032-9

Sakurai, G. \& Kasuya, E. (2008). The costs of harassment in the adzuki bean beetle. Animal Behaviour, 75, 1367-1373. doi:10.1016/ j.anbehav.2007.09.010

Sánchez-Guillén, R. A., Wellenreuther, M., Chávez-Ríos, J. R., Beatty, C. D., Rivas-Torres, A., Velasquez-Velez, M. \& Cordero-Rivera A. (2017). Alternative reproductive strategies and the maintenance of female color polymorphism in damselflies. Ecology and Evolution, 7, 5592-5602. doi:10.1002/ece3.3083

Sanchez-Guillen, R. A., Wellenreuther, M., Cordero-Rivera, A. \& Hansson, B. (2011). Introgression and rapid species turnover in sympatric damselflies. BMC Evol. Biol., 11, 210. doi:10.1186/ 1471-2148-11-210

Schultz, T. D. \& Fincke, O. M. (2013). Lost in the crowd or hidden in the grass: signal apparency of female polymorphic damselflies in alternative habitats. Animal Behaviour, 86, 923-931. doi:10.1016/j.anbehav.2013.08.008

Schwagmeyer, P. L. (1995). Searching today for tomorrow's mates. Animal Behaviour, 50, 159-161. doi:10.1016/0003-3472(95) 80136-7

Siepielski, A. M., McPeek, S. J. \& McPeek, M. A. (2018). Female mate preferences on high-dimensional shape variation for male species recognition traits. Journal of Evolutionary Biology, 31, 12391250. doi:10.1111/jeb.13302

Singer, F., Riechert, S. E., Xu, H. F., Morris, W., Becker, E., Hale, J. A. \& Noureddine, M. S. (2000). Analysis of courtship success in the funnel-web spider Agelenopsis aperta. Behaviour, 137, 93-117. doi:10.1163/156853900501890

Stewart-Fox, D. M. \& Whiting, M. J. (2005). Male dwarf chameleons assess risk of courting large, aggressive females. Biology Letters, 1, 231-234. doi:10.1098/rsbl.2005.0299

Sudaresan, S. R., Fischhoff, I. R. \& Rubenstein, D. I. (2007). Male harassment influences female movements and associations in 
Grevy's zebra (Equus grevyi). Behavioral Ecology, 18, 860-865. doi:10.1093/beheco/arm055

Tennessen, K. J. (1975). Reproductive behavior and isolation of two sympatric coenagrionid damselflies in Florida. Ph.D. thesis, Univ. Florida, Gainesville.

Tennessen, K. J. (1982). Review of reproductive isolating barriers in Odonata. Advances in Odonatology, 1, 251-265.

Van Gossum, H., Sherratt, T. N. \& Cordero-Rivera, A. (2008). The evolution of sex-limited colour polymorphism. In Cordoba-Aguilar, A. (Ed.), Dragonflies and Damselflies: Model Organisms for Evolutionary Research. pp. 219-229. Oxford University Press. doi:10.1093/acprof:oso/9780199230693.003.0017

Van Gossum, H., Stoks, R. \& De Bruyn, L. (2001). Frequency-dependent male mate harassment and intra-specific variation in its avoidance by females of the damselfly Ischnura elegans. Behavioral Ecology and Sociobiology, 51, 69-75. doi:10.1007/ s002650100418

Waage, J. K. (1984). Female and male interactions during courtship in Calopteryx maculata and C. dimidiata (Odonata: Calopterygidae): Influence of oviposition behaviour. Animal Behaviour, 32, 400-404. doi:10.1016/S0003-3472(84)80276-6

Wirklund, K. \& Forsber, J. (1986). Courtship and male discrimination between virgin and mated females in the orange tip butterfly Anthocharis cardamines. Animal Behaviour, 34, 328-332. doi:10.1016/S0003-3472(86)80100-2

$\mathrm{Xu}$, M. \& Fincke, O. M. (2011). Tests of the harassment-reduction function and frequency-dependent maintenance of a femalespecific color polymorphism in a damselfly. Behavioral Ecology and Sociobiology, 65, 1215-1227. doi:10.1007/s00265-0101134-6

Zuur A, leno, E. N., Walker, N., Saveliev, A. A. \& Smith, G. M. (2009). Mixed effects models and extensions in ecology with $R$. Springer Science \& Business Media. doi:10.1007/978-0-387-87458-6

\section{Supplementary material}

Supplementary Figure S1. Proportions of responses after male detection, categorized as acceptance, avoidance behaviors, and refusal signals, from focal females in the virgin, mated, and oviposited treatments. 